\title{
Effective and cheap removal of leukocytes and platelets from Plasmodium vivax infected blood
}

\author{
Kanlaya Sriprawat ${ }^{\dagger 1}$, Supaporn Kaewpongsri ${ }^{\dagger 1}$, Rossarin Suwanarusk ${ }^{2}$, \\ Mara L Leimanis ${ }^{1}$, Usa Lek-Uthai ${ }^{3}$, Aung Pyae Phyo ${ }^{1}$, Georges Snounou ${ }^{2,4,5,6}$, \\ Bruce Russell *2,7, Laurent Renia ${ }^{2}$ and François Nosten ${ }^{1,8,9}$
}

\begin{abstract}
Address: ${ }^{1}$ Shoklo Malaria Research Unit, Mae Sod, PO Box 46, Tak 63110, Thailand, ${ }^{2}$ Singapore Immunology Network (SIgN), IMMUNOS Building 3-4, BIOPOLIS, 8A Biomedical Grove, 138648, Singapore, ${ }^{3}$ Department of Parasitology and Entomology, Faculty of Public Health, Mahidol University, 420/1 Rajvithi Road, Rajthewee, Bangkok 10400, Thailand, "4Département de Parasitologie, INSERM UMR S 945, Hôpital Pitié-Salpêtrière, Paris, France, ${ }^{5}$ Faculté de Médecine Pitié-Salpêtrière, Université Pierre et Marie Curie, 4 place jussieu, 75005, Paris, France, ${ }^{6}$ Department of Microbiology, Laboratory of Molecular and Cellular Parasitology, Faculty of Medicine, National University of Singapore, 5 Science Drive 2, 117597, Singapore, ${ }^{7}$ Nano Biomechanics Laboratory, Division of Bioengineering and Department of Mechanical Engineering, National University of Singapore, 10 Kent Ridge Crescent, 119260, Singapore, ${ }^{8}$ Medicine, Nuffield Department of Clinical Medicine, University of Oxford, CCVTM, Oxford, OX3 7LJ, UK and 'Faculty of Tropical Medicine, Mahidol University, 420/6 Rajvithi Road, Bangkok, 10400, Thailand

Email: Kanlaya Sriprawat - poo@shoklo-unit.com; Supaporn Kaewpongsri - jum@shoklo-unit.com; Rossarin Suwanarusk - rossarin_suwanarusk@immunol.a-star.edu.sg; Mara L Leimanis - mara@tropmedres.ac; Usa LekUthai - phulu@mahidol.ac.th; Aung Pyae Phyo - aungpyaephyo@shoklo-unit.com; Georges Snounou - snounou@mnhn.fr; Bruce Russell* - bruce_russell@immunol.a-star.edu.sg; Laurent Renia - renia_laurent@immunol.a-star.edu.sg; François Nosten - francois@tropmedres.ac

* Corresponding author †Equal contributors
\end{abstract}

Published: 2 June 2009

Malaria Journal 2009, 8:1/5 doi:10.1 I86/1475-2875-8-1/5

This article is available from: http://www.malariajournal.com/content/8/I/II5

(C) 2009 Sriprawat et al; licensee BioMed Central Ltd.

This is an Open Access article distributed under the terms of the Creative Commons Attribution License (http://creativecommons.org/licenses/by/2.0), which permits unrestricted use, distribution, and reproduction in any medium, provided the original work is properly cited.
Received: 4 February 2009

Accepted: 2 June 2009

\begin{abstract}
Background: Investigations of Plasmodium vivax are restricted to samples collected from infected persons or primates, because this parasite cannot be maintained in in vitro cultures. Contamination of $P$. vivax isolates with host leukocytes and platelets is detrimental to a range of ex vivo and molecular investigations. Easy-to-produce CFII cellulose filters have recently provided us with an inexpensive method for the removal of leukocytes and platelets. This contrasted with previous reports of unacceptably high levels of infected red blood cell (IRBC) retention by CFII. The aims of this study were to compare the ability of CFII cellulose filters and the commercial filter Plasmodipur at removing leukocyte and platelet, and to investigate the retention of $P$. vivax IRBCs by CFI I cellulose filtration.
\end{abstract}

Methods and Results: Side-by-side comparison of six leukocyte removal methods using blood samples from five healthy donor showed that CFII filtration reduced the mean initial leukocyte counts from $9.4 \times 10^{3}$ per $\mu \mathrm{l}[95 \% \mathrm{Cl} 5.2-13.5]$ to $0.01 \times 10^{3}[95 \% \mathrm{Cl} 0.0 \mathrm{I}-0.03]$. The CFII was particularly effective at removing neutrophils. CFII treatment also reduced initial platelet counts from $21 \mathrm{l} .6 \times 10^{3}$ per $\mu \mathrm{l}[95 \% \mathrm{Cl} 107.5-3 \mid 5.7]$ to $0.8 \times 10^{3}$ per $\mu \mathrm{l}[95 \% \mathrm{Cl}-0.7-2.2]$. Analysis of 30 $P$. vivax blood samples before and after CFII filtration showed only a minor loss in parasitaemia $(\leq$ $7.1 \%$ of initial counts). Stage specific retention of $P$. vivax IRBCs was not observed.

Conclusion: CFII filtration is the most cost and time efficient method for the production of leukocyte- and platelet-free $P$. vivax-infected erythrocytes from field isolates. 


\section{Background}

The emergence of drug resistance[1] and the renewed awareness of severity in vivax malaria[2] is spurring efforts to better understand this important pathogen. However, exploiting the recently published genome[3] and transcriptome[4] of Plasmodium vivax still relies on the use of infected blood samples collected from patients or experimentally infected simians, because it is not yet possible to continuously culture this parasite.

Removal of leukocytes and other components from infected blood samples is an important prerequisite for a number of investigations. Sequencing the parasite's genome can be significantly hampered by the relatively large quantities of host DNA present in white blood cells. Furthermore, it has been shown that the leukocytes present in samples can phagocytise, damage and potentially destroy malaria parasites under ex vivo investigations[5,6]. Antimicrobial and biochemical studies of infectious diseases may also be confounded by the significant metabolic activity of leukocytes in the sample of interest. Recently, the bioethical regulations in many countries mandate the removal of human leukocytes from infected blood samples, before transfer to other countries, in order to curb the possibility of unauthorized human genomic research. Other blood components are best removed from the collected blood before in vitro testing. Platelets often bind to and degranulate on contact with infected red blood cells (IRBCs) adversely affecting the parasite's ex vivo development[7].

The wide range of leukocyte removal techniques that have been developed since the 1950s, are mostly based on differential centrifugation or on column filtration. Differential density centrifugation using sucrose solutions, Percoll $^{\mathrm{TM}}$, Nycodenz ${ }^{\mathrm{TM}}$, Ficoll ${ }^{\mathrm{TM}}$ and Lymphoprep ${ }^{\mathrm{TM}}$ (Greiner Bio-One $e^{\circledR}$ are particularly useful when a viable leukocyte fraction is needed for subsequent immunological investigations. However, these methods are particularly time consuming. It is generally agreed that column filtration methods are a more practical, rapid and effective method for the removal of leukocytes [8-10]. Custom-made CF11 cellulose powder columns are significantly less expensive than commercial filters such as Plasmodipur, however, it has been reported that CF11 retains some IRBCs and in particular mature asexual stages (trophozoite and schizont) of $P$. vivax[11]. This contrasts with observations made in recent studies where the use of CF11 cellulose filters with $P$. vivax samples did not result in a high loss of mature stages after filtration [12-14].

The two aims of this study were to compare the efficacy of leukocyte and platelet removal efficacy of CF11-based filters and of Plasmodipur, and to investigate whether stage specific retention of $P$. vivax IRBCs occurs through CF11 cellulose filtration.

\section{Methods \\ CFII column construction}

A $10 \mathrm{ml}$ syringe (with the plunger removed) was tipped with two $1 \mathrm{~cm}^{2}$ pieces of Grade 105 lens cleaning tissue (Whatman $^{\circledR}$ ). The tissue was placed in the syringe so as to cover the outlet lumen. Only syringes with a centred rather than an offset outlet should be used. Ten $\mathrm{ml}$ of loosely packed of CF11 cellulose powder (Whatman ${ }^{\circledR}$ ) were added to the syringe and then packed down to $\sim 5.5$ $\mathrm{ml}$ of packed cellulose. The tip and bottom of the syringe were covered with aluminium foil, and then autoclaved. When ready to use, the CF11 column was wetted with $\sim 5$ $\mathrm{ml}$ of isotonic phosphate buffered saline (PBS) solution (without $\mathrm{Ca}^{2+}$ and $\mathrm{Mg}^{2+}, \mathrm{pH} 7.3$ ).

\section{Sample collection and processing}

Due to the limited quantity of $P$. vivax IRBC healthy donor blood was used for the initial side-by-side comparisons of leukocytes and platelet removal methods. Ten $\mathrm{ml}$ of whole blood were collected onto Lithium heparin from five healthy donors by venepuncture. The whole blood was centrifuged at $500 \mathrm{~g}$ for $5 \mathrm{~min}$ at room temperature. The plasma supernatant was removed, but the buffy coat fraction containing white blood cells (WBC) was added back to the red blood cell (RBC) pellet. The RBC+WBC mix from each donor was divided into five two $\mathrm{ml}$ portions to which an equal volume of RPMI was added with gentle mixing. The first tube was used as the control for this study. The $2^{\text {nd }}$ tube was centrifuged again as above and the PBS supernatant and buffy coat carefully removed from the packed RBC, this tube was the 'Buffy Coat Removal' treatment. The $3^{\text {rd }}$ tube was loaded into a five $\mathrm{ml}$ syringe (the plunger removed) and mounted onto a Plasmodipur $^{\text {TM }}$ filter (Euro-Diagnostica ${ }^{\circledR}$ ) that was pre-rinsed with a sterile PBS solution. Then gentle pressure was applied to the syringe attached to the Plamodipur unit and the filtered RBC/PBS (50\% haematocrit) mix was collected as the 'Plasmodipur' treatment. The $4^{\text {th }}$ and $5^{\text {th }}$ tubes were added to PBS-wetted CF11 columns. The filtered $4^{\text {th }}$ sample was then collected as the 'CF11' treatment. The filtered $5^{\text {th }}$ sample was then added to another unused CF11 column (pre-wetted with $5 \mathrm{ml}$ of PBS). The double filtered $5^{\text {th }}$ sample was the 'CF $11 \times 2^{2}$ treatment. In addition to the above samples, three more healthy volunteers were recruited, and $8 \mathrm{ml}$ of whole blood were collected onto Lithium heparin. This blood was processed as above and divided into four $2 \mathrm{ml}$ samples. The first and $2^{\text {nd }}$ tubes were processed as described above for the control and the 'CF11' treatments, respectively. The contents of the $3^{\text {rd }}$ tube were layered over $2 \mathrm{ml}$ of Lymphoprep ${ }^{\mathrm{TM}}$ (Greiner Bio-One ${ }^{\circledast}$ ) and centrifuged at $600 \mathrm{~g}$ for $20 \mathrm{~min}$ at $20^{\circ} \mathrm{C}$, the leukocytes that banded at the interface were 
removed using a pipette, and the supernatant RBC fraction was the 'Lymphoprep' treatment. The $4^{\text {th }}$ tube was processed as above for the 'Lymphoprep' treatment, but then subsequently processed using the 'Plasmodipur' treatment protocol described above. This final sample was called the 'Lymphoprep and Plasmodipur' treatment.

Please note; unless specifically stated, the term 'CF11 filtration' involved only a single CF11 filter, as opposed to 'CF11x2' which involved processing the sample using two CF11 columns.

Complete blood counts of the control samples and the suspensions obtained from the six treatments were conducted using an Automated Hematology Analyzer (Model pocH-100i, Sysmex Company) and by microscopic examination (x100 oil immersion) of Giemsa-stained thick (250 fields) and thin smears (450 fields). The data from the thin smears were used for differential lymphocyte counts.

\section{Effect of CFI I filtration on P. vivax isolates}

Thick and thin smears were routinely made for the preand post-CF11 filtration from each of the P. vivax isolates collected, prior to ex vivo drug sensitivity testing at the Shoklo Malaria Research Unit (SMRU), Mae Sod, Thailand. The pre- and post-CF11 filtration, thick and thin smears from 30 randomly selected isolates collected during 2008 were examined as follows. Parasitaemias were determined from the number of IRBC per ten $100 \times$ oil immersion fields (200 RBC per field) on the thin film. The percentage of early (ring-like parasites with a single chromatin dot) and mature (amoeboid-like cytoplasm or presence of haemozoin) asexual stages was determined from examining 200 parasites in the thick smears under 100x oil immersion. Due to their very low numbers in the preand post-filtration smears schizonts (parasites with 3 or more chromatin dots and haemozoin) were combined with the mature stage count. Gametocyte counts were too low for statistical comparison.

Parametric analysis of non-paired data was calculated using one-way analysis of variance. Non-parametric analysis of the paired data was performed using Wilcoxon or Friedman's tests and post-hoc analysis using Dunn's test (GraphPad Prism 5.01).

The clinical IRBC samples examined in this study were collected under the following ethical guidelines in the approved protocol OXTREC 027-05 (University of Oxford, Centre for Clinical Vaccinology and Tropical Medicine, UK)

\section{Results and discussion \\ Cost- and time-effective removal of leukocytes}

Plasmodipur filters were the most rapid method for the filtration of donor blood with 10 min per isolate as compared to the $\sim 20$ min per isolate required for CF11 filtration. A Plasmodipur filtering unit costs 50-55 USD while a single CF11 column could be made at a total cost of $\sim 1$ USD. The effectiveness of the two types of columns to remove leukocytes and platelets from clinical blood samples was then assessed (Figure 1A and 1B). Filtration on CF11 and Plasmodipur reduced the mean initial leukocyte counts from $9.4 \times 10^{3}$ per $\mu$ l [95\%CI 5.2-13.5] to $0.01 \times 10^{3}$ [95\%CI $\left.0.01-0.03\right]$ and $0.7 \times 10^{3}$ per $\mu \mathrm{l}$ [95\%CI 0.4-1.8] respectively (Figure 1A). Filtration on CF11 was particularly effective at removing platelets, reducing the platelet count from $211.6 \times 10^{3}$ per $\mu \mathrm{l}$ [95\%CI 107.5-315.7] to $0.8 \times 10^{3}$ per $\mu$ l [95\%CI -0.7$2.2]$, a significantly greater platelet reduction when compared to the mean platelet count of the Plasmodipur filtrate which was $14.0 \times 10^{3}$ per $\mu$ l [95\%CI -2.3-30.5]) $(\mathrm{p}=$ 0.02 ). Only by pre-processing the blood sample with Lymphoprep prior to Plasmodipur filtration was it possible to reduce the mean leukocyte $\left(0.3 \times 10^{3}\right.$ per $\mu$ l [95\%CI $-1.1-1.8])$ and platelet $\left(0.0 \times 10^{3}\right.$ per $\left.\mu \mathrm{l}\right)$ contamination to the same levels as that obtained by CF11 filtration. However, pre-treatment with Lymphoprep adds another 50 mins and a further $~ 8-9$ USD to procedure, thus negating the benefits of the relatively speedier Plasmodipur filtration. It was interesting to note that the composition of the contaminating leukocytes in the suspension obtained after Lymphoprep/Plasmodipur or CF11 filtration differed greatly. Leukocyte contamination in the Lymphoprep/Plamodipur filtrate was predominantly neutrophils (98\%) with the remainder made up of lymphocytes and basophils/monocytes (Figure 2). By contrast, no neutrophils were found in the CF11 filtrate where the small number of contaminating leukocytes was either lymphocytes (59\%) or basophils/eosinophils (41\%). The specific removal of neutrophils by CF11 is of particular advantage in ex vivo culture, where neutrophils readily phagocytise maturing IRBCs [6].

\section{The effect of CFI I filtration on P. vivax parasite numbers and stages}

Filtration of $P$. vivax infected isolates resulted in median parasitaemia change of $-0.1 \%$ [IQR -0.3-0.03] (Figure $3 \mathrm{~A})$. This corresponds to a $7.14 \%$ reduction in IRBCs from the initial median parasitaemia of $0.7 \%$ [IQR $0.38-1.12$ ] to a post filtration median parasitaemia of $0.65 \%$ [IQR $0.30-1.0]$ ] $(p=0.01)$. The magnitude of IRBC loss was much less than the major losses previously reported for CF11 filtration, namely from a starting parasitaemia of $0.37 \%$ to $0.18 \%$ in the filtrate for one sample and $0.43 \%$ to $0.01 \%$ for the other, representing a $52 \%$ and $98 \%$ reduction in parasitaemia respectively [11]. It was further 
A

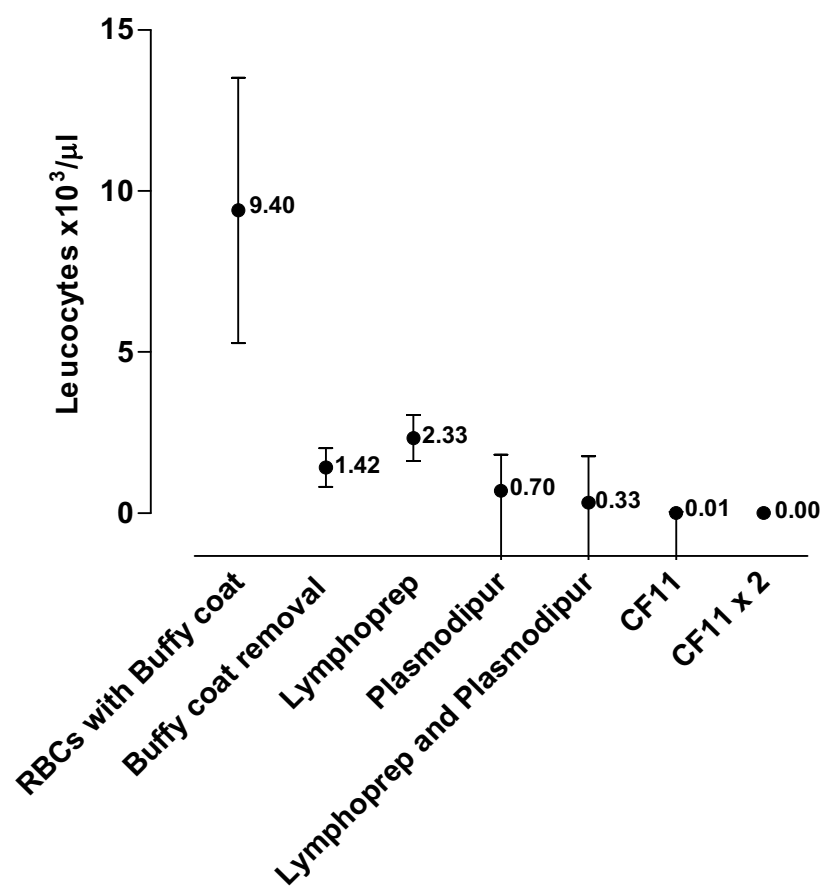

B

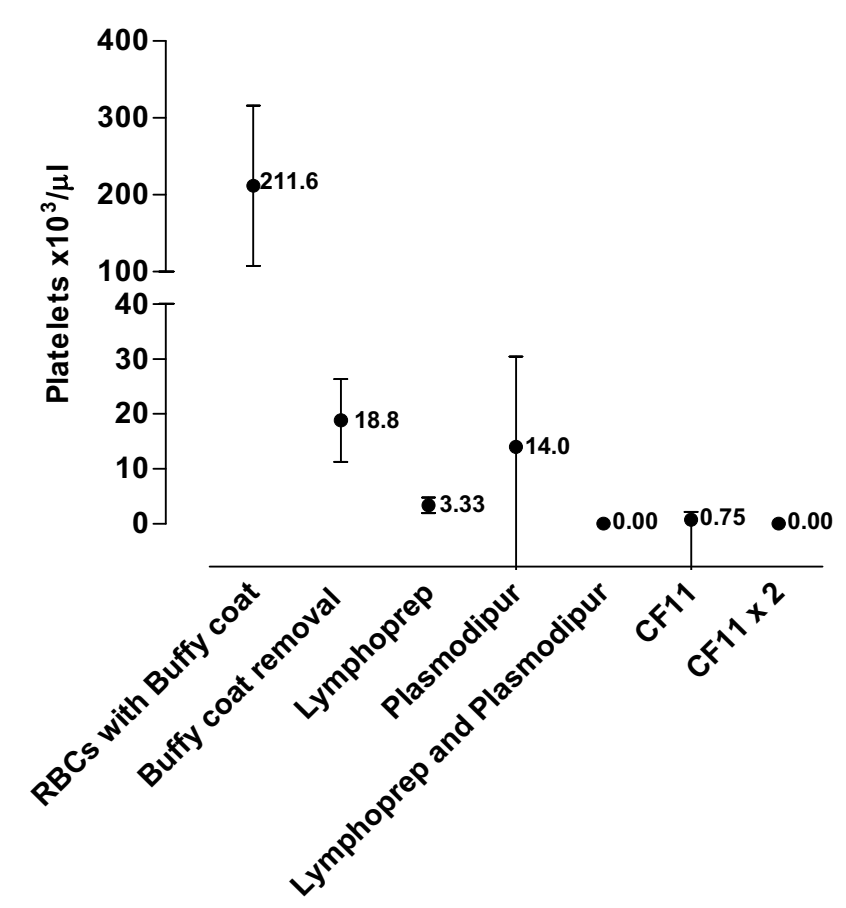

Figure I

The comparative efficacy of six methods for removing leukocytes (A) and platelets (B) from five healthy donor blood samples (repeated measures) prior to buffy coat removal. Leukocyte counts and platelet mean counts $\times 10^{3} \mu l$ of whole blood [+/-95\% Cl]; analysis by Automated Hematology Analyzer (Model pocH-I00i, Sysmex Company). 


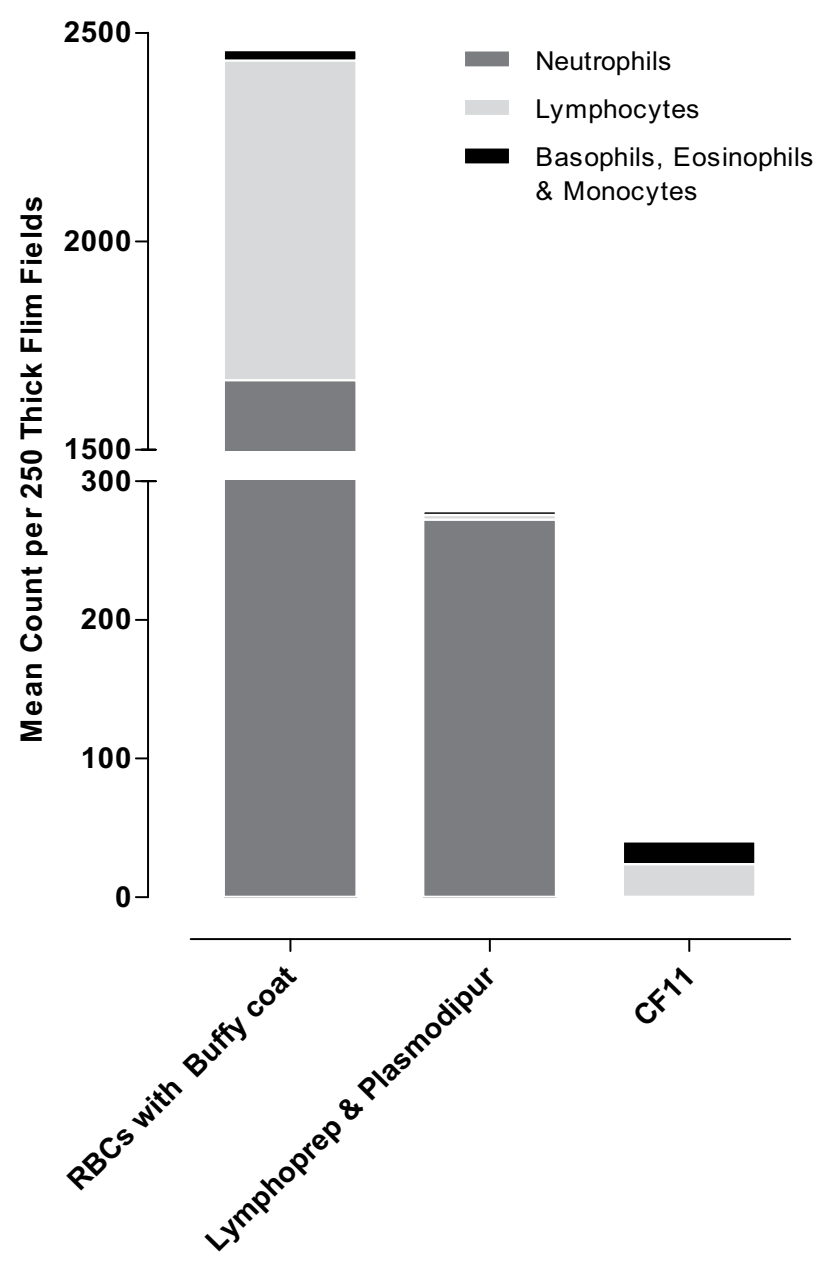

Figure 2

Comparison of leukocyte composition of five healthy donor blood samples before and after treatment with Lymphoprep and Plasmodipur and CFI I methods. Leukocyte counts are expressed as Mean Count per 250 Thick Films (100× oil immersion).

reported that CF11 selectively retained mature trophozoites and schizonts, with only ring stages passing through the CF11 unimpeded[11]. In this study we failed to observe any selective retention of mature $P$. vivax stages, the median pre- and post-filtration composition of late stages in the $P$. vivax samples was $17 \%$ and $19 \%$ respectively. The median change in the composition of late stages pre- and post-filtration was an increase of $1.0 \%$ [IQR -4.2 to 4.2] ( $p=0.06$ ) (Figure 3B). This is consistent with our experience with routine use of CF11 filtration of $P$. vivax isolate where the loss of mature forms were not noted $[12,13,15]$, and where CF11 filtration did not effect $P$. vivax maturation of early or late stage trophozoites.
It should be noted that equally satisfactory removal of leukocytes and platelets, with little loss of parasites, were obtained when the PBS solution was used to wash and resuspend the blood and the CF11 columns was replaced by RPMI or McCoy's 5A medium $\left(\mathrm{GIBCO}^{\circledast}\right)$

\section{Conclusion}

Custom-made CF11 filtration provides a cost effective method for the removal of leukocytes from $P$. vivax clinical isolates. The small, non stage specific, reduction in parasitaemia due to CF11 filtration has done little to hamper its application to a range of recent $P$. vivax studies [12$14,16]$, notably the recent report on the $P$. vivax transcriptome[4]. Although the report of high parasite losses due to CF11 filtration were only based on two samples [11], the magnitude of the losses was substantial. It is unlikely that variations in the quality of the CF11 powder account for the discrepancy between this observation and ours. The composition of the buffers used to resuspend and wash the blood samples and the column might, on the other hand, substantially modify the binding properties of the CF11 powder to different cell types. This is evident from the first report of $P$. vivax retention by CF11 [17] where the mere addition of $2 \mathrm{mM}$ EDTA improved the recovery of IRBCs. Furthermore, in our experience the quantity of CF11 powder per ml of whole blood, the degree of column compaction, as well as the amount and extent of washing, influence the efficacy of the protocol. If the 'leukocyte free' status of the IRBC preparation is a priority, we recommend the $\mathrm{CF} 11 \mathrm{x} 2$ protocol (Figure 1A). Notwithstanding the detailed description we provide for our protocol, we strongly recommend that the procedure be validated on test samples before its routine adoption.

An additional benefit of WBC and platelet filtration, irrespective of the method chosen, is that it aids in the microscopic examination of thick films. Thick films made from filtered isolates produce clear 'noise-free' thick films (Figure 4). This may also be crucial in the successful development of digital recognition software for automating parasite counts [18].

\section{Competing interests}

The authors declare that they have no competing interests. 
A

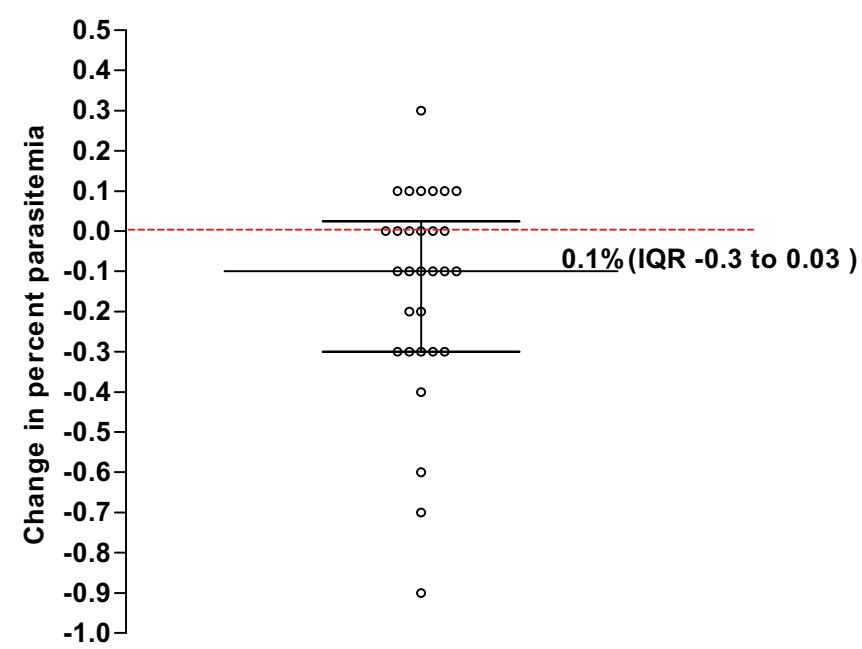

B

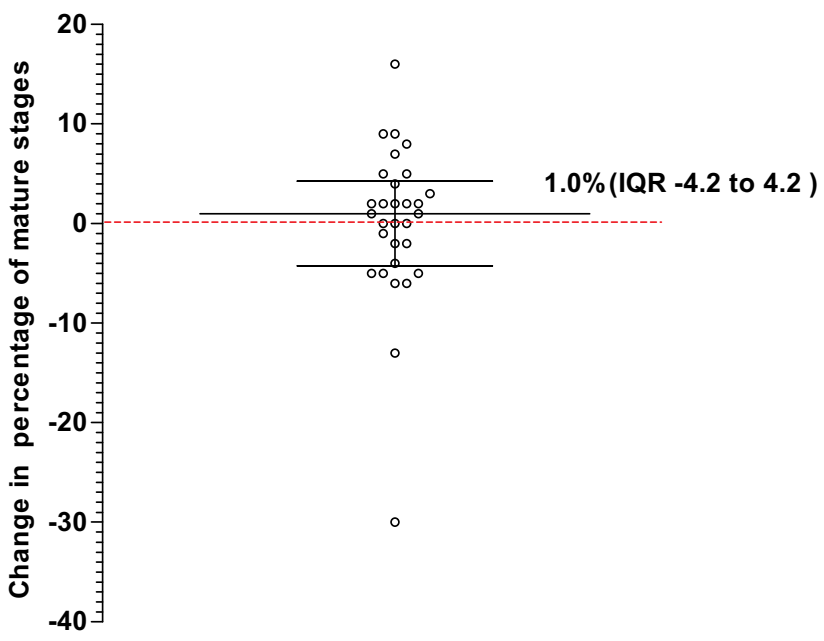

Figure 3

The effect of CF I I filtration on the parasitaemia (A) and developmental stage composition (B) of 30 Thai Plasmodium vivax isolates. The effect of filtration is expressed as a change in the percentage parasitaemia (IRBC per I0 thin film fields at $100 \times$ oil immersion) or percentage mature $P$. vivax erythrocytic stages [(mature stages/(early stages + mature stages)*100)] relative to the blood stages prior to CFI I filtration (no change denoted by the red broken line).

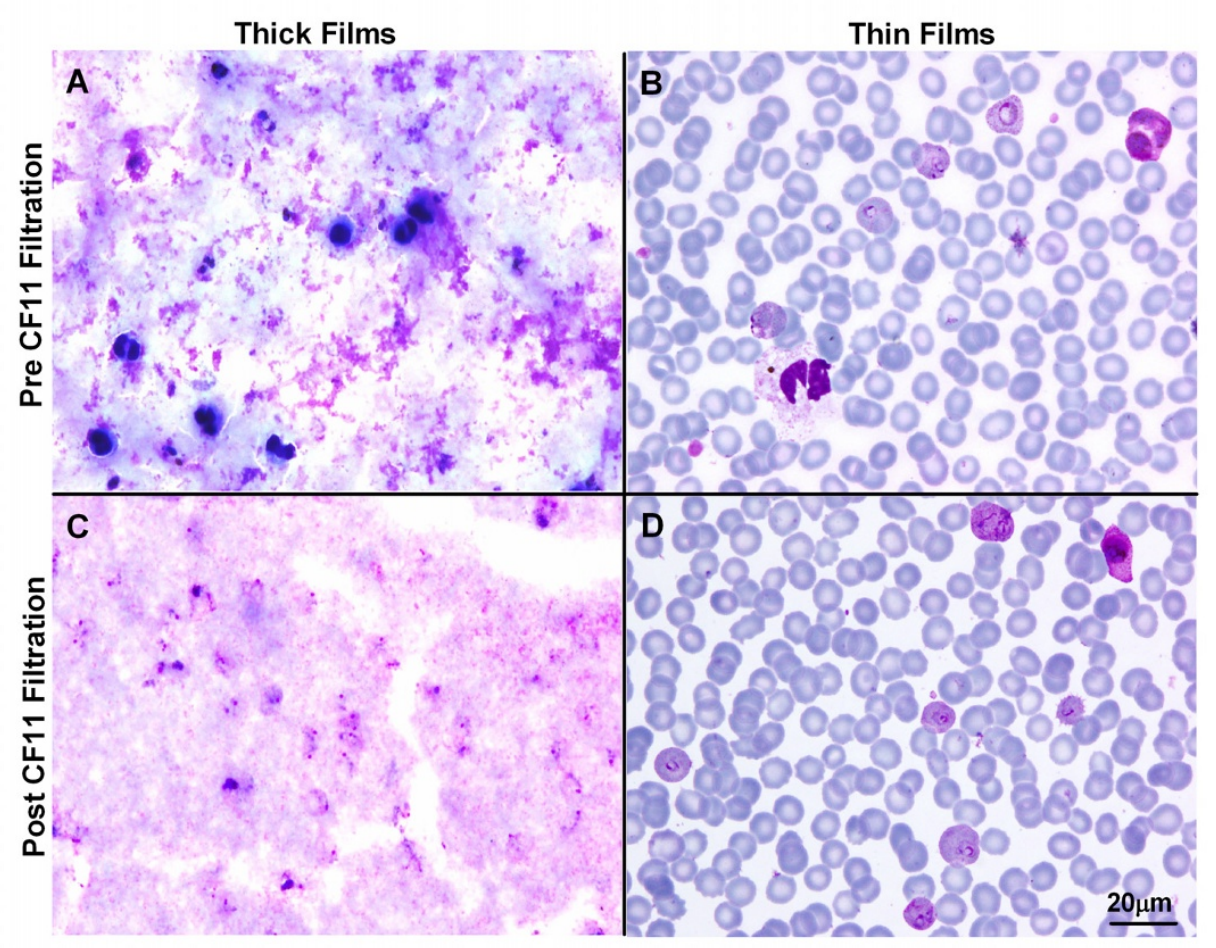

Figure 4

The effect of CF I I filtration on thick and thin Giemsa stained films. Photomicrographs of thick (A\&C) and thin (B\&D) films before and after CFI I filtration (I00x oil immersion, Scale bar $=20 \mu \mathrm{m}$ ). 


\section{Authors' contributions}

KS, SK and RS helped design this study, optimized and conducted the experiments, microscopy, and drafted the manuscript. UL and MLL coordinated the field studies, sample collection, and provided intellectual guidance though out this study. BR conceived the study, designed and participated in the experiments, was the cross check microscopist, responsible for photomicrographs and figure production, and initial drafting of the manuscript. GS provided invaluable intellectual input through out the study and significant contributions to the production of the final manuscript. APP and FN coordinated the clinical support and ethical approval. LR and FN jointly directed the study as a whole, providing major intellectual guidance though out this study and during manuscript preparation. All authors read and approved the final manuscript.

\section{Acknowledgements}

The authors thank staff of the SMRU. SMRU is part of the Mahidol Oxford Research Unit (MORU) supported by the Wellcome Trust of Great Britain (FN). This study was also funded by the Faculty of Public Health, Mahidol University (UL) and the Singapore Agency for Science Technology and Research (A*STAR) (LR).

\section{References}

I. Baird JK: Real-world therapies and the problem of vivax malaria. N Engl J Med 2008, 359:260I-2603.

2. Price RN, Tjitra E, Guerra CA, Yeung S, White NJ, Anstey NM: Vivax malaria: neglected and not benign. Am J Trop Med Hyg 2007, 77(6 Suppl):79-87.

3. Carlton JM, Adams JH, Silva JC, Bidwell SL, Lorenzi H, Caler E, Crabtree J, Angiuoli SV, Merino EF, Amedeo P, Cheng Q, Coulson RM, Crabb BS, Del Portillo HA, Essien K, Feldblyum TV, FernandezBecerra C, Gilson PR, Gueye AH, Guo X, Kang'a S, Kooij TW, Korsinczky M, Meyer EV, Nene V, Paulsen I, White O, Ralph SA, Ren Q, Sargeant TJ, Salzberg SL, Stoeckert CJ, Sullivan SA, Yamamoto MM, Hoffman SL, Wortman JR, Gardner MJ, Galinski MR, Barnwell JW, Fraser-Liggett CM: Comparative genomics of the neglected human malaria parasite Plasmodium vivax. Nature 2008, 455:757-763.

4. Bozdech Z, Mok S, Hu G, Imwong M, Jaidee A, Russell B, Ginsburg H, Nosten F, Day NP, White NJ, Carlton JM, Preiser PR: The transcriptome of Plasmodium vivax reveals divergence and diversity of transcriptional regulation in malaria parasites. Proc Natl Acad Sci USA 2008, I 05: I 6290- I 6295.

5. Celada A, Cruchaud A, Perrin LH: Phagocytosis of Plasmodium falciparum-parasitized erythrocytes by human polymorphonuclear leukocytes. J Parasitol 1983, 69:49-53.

6. Brown J, Smalley ME: Inhibition of the in vitro growth of Plasmodium falciparum by human polymorphonuclear neutrophil leucocytes. Clin Exp Immunol I 98I, 46:106-109.

7. Peyron F, Polack B, Lamotte D, Kolodie L, Ambroise-Thomas P: Plasmodium falciparum growth inhibition by human platelets in vitro. Parasitology 1989, 99:317-322.

8. Richards WH, Williams SG: The removal of leucocytes from malaria infected blood. Ann Trop Med Parasitol 1973, 67:249-250.

9. Mons B, Boorsma EG, Ramesar J, Janse C]: Removal of leucocytes from malaria-infected blood using commercially available filters. Ann Trop Med Parasitol 1988, 82:621-623.

10. Williamson J, Cover B: Removal of white blood cells from gametocyte-, schizont-, trophozoite- and ring stages of Plasmodium falciparum. Trans $R$ Soc Trop Med Hyg 197I, 65:4I6.

II. Janse CJ, Camargo A, Del Portillo HA, Herrera S, Kumlien S, Mons B, Thomas A, Waters AP: Removal of leucocytes from Plasmodium vivax-infected blood. Ann Trop Med Parasitol 1994, 88:213-216.
12. Lek-Uthai U, Suwanarusk R, Ruengweerayut R, Skinner-Adams TS, Nosten F, Gardiner DL, Boonma P, Piera KA, Andrews KT, Machunter B, McCarthy JS, Anstey NM, Price RN, Russell B: Stronger activity of human immunodeficiency virus type I protease inhibitors against clinical isolates of Plasmodium vivax than against those of $\boldsymbol{P}$. falciparum. Antimicrob Agents Chemother 2008, 52:2435-244I.

13. Russell B, Chalfein F, Prasetyorini B, Kenangalem E, Piera K, Suwanarusk R, Brockman A, Prayoga $P$, Sugiarto $P$, Cheng Q, Tjitra E, Anstey NM, Price RN: Determinants of in vitro drug susceptibility testing of Plasmodium vivax. Antimicrob Agents Chemother 2008, 52:1040-1045.

14. Suwanarusk R, Chavchich M, Russell B, Jaidee A, Chalfein F, Barends M, Prasetyorini B, Kenangalem E, Piera KA, Lek-Uthai U, Anstey NM, Tjitra E, Nosten F, Cheng Q, Price RN: Amplification of pvmdr I associated with multidrug-resistant Plasmodium vivax. J Infect Dis 2008, 198: 1558-1564.

15. Suwanarusk R, Russell B, Chavchich M, Chalfein F, Kenangalem E, Kosaisavee V, Prasetyorini B, Piera KA, Barends M, Brockman A, LekUthai U, Anstey NM, Tjitra E, Nosten F, Cheng Q, Price RN: Chloroquine resistant Plasmodium vivax: in vitro characterisation and association with molecular polymorphisms. PLOS ONE 2007, 2:el089.

16. Handayani S, Chiu DT, Tjitra E, Kuo JS, Lampah D, Kenangalem E, Renia L, Snounou G, Price RN, Anstey NM, Russell B: High deformability of Plasmodium vivax-infected red blood cells under microfluidic conditions. J Infect Dis 2009, I 99:445-450.

17. Waki S, Suzuki M: Concentration of Plasmodium vivax-infected erythrocytes. Ann Trop Med Parasitol 1986, 80:125-126.

18. Le MT, Bretschneider TR, Kuss C, Preiser PR: A novel semi-automatic image processing approach to determine Plasmodium falciparum parasitemia in Giemsa-stained thin blood smears. BMC Cell Biol 2008, 9:I5.

Publish with Bio Med Central and every scientist can read your work free of charge

"BioMed Central will be the most significant development for disseminating the results of biomedical research in our lifetime. "

Sir Paul Nurse, Cancer Research UK

Your research papers will be:

- available free of charge to the entire biomedical community

- peer reviewed and published immediately upon acceptance

- cited in PubMed and archived on PubMed Central

- yours - you keep the copyright 